\title{
Modified internal ligation of the left atrial appendage
}

Dawn S. Hui, MD, and Richard Lee, MD, MBA, St Louis, Mo

\author{
From the Center for Comprehensive Cardiovascular Care, Saint Louis University, St Louis, Mo. \\ Disclosures: Authors have nothing to disclose with regard to commercial support. \\ Received for publication Feb 28, 2017; revisions received March 23, 2017; accepted for publication April 18, \\ 2017; available ahead of print June 9, 2017. \\ Address for reprints: Richard Lee, MD, MBA, 3635 Vista Ave, DT 13th Floor, St Louis, MO 63110 (E-mail \\ rlee@slu.edu). \\ J Thorac Cardiovasc Surg 2017;154:847-8 \\ $0022-5223 / \$ 36.00$ \\ Copyright (C) 2017 Published by Elsevier Inc. on behalf of The American Association for Thoracic Surgery \\ http://dx.doi.org/10.1016/j.jtcvs.2017.04.077
}

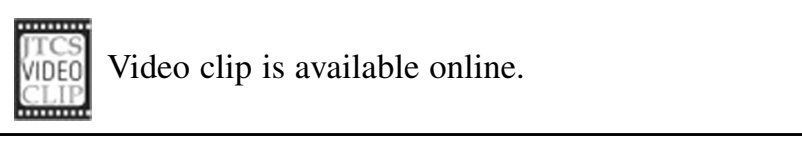

Elimination of the left atrial appendage (LAA) is as effective as anticoagulation for stroke prevention in patients with atrial fibrillation. ${ }^{1}$ A variety of techniques for LAA elimination have been described; however, case series have demonstrated high failure rates both intraoperatively and long term. A recent randomized study comparing internal ligation, stapled excision, and surgical excision showed an overall (early plus late) elimination failure rate of $47 \%$, with no significant difference among the techniques. ${ }^{2}$ We present a novel surgical technique for management of the LAA, consisting of inversion, compression, and exclusion.

The left atrium is approached through an interatrial groove or transseptal approach. After any mitral procedures have been completed, the LAA is inspected for thrombus. It is then inverted into the field (Figure 1, inset; and Video 1). A 4-0 pledgeted double-armed polypropylene suture ("compression suture") is placed in the tip of the appendage, brought out at the appendage base, and left untied (Figure 1). This is followed by a running double-layer 4-0 polypropylene suture to close the orifice of the appendage. The inverting suture is then tied down to bring the tip down to the base and decrease tension on the appendage (Figure 2).

\section{DISCUSSION}

Surgical options for LAA exclusion include excision and oversewing, external closure with stapling or a clip, and internal ligation. Each of these techniques carries its own risk and durability profile. The technique described here offers a new option for surgical management of the LAA. It is

\section{SURGICAL TECHNIQUE}

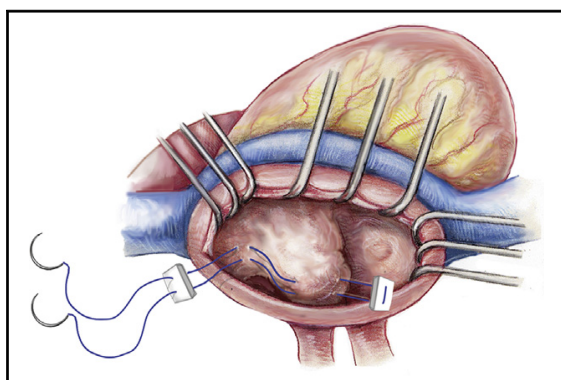

Modified internal ligation of the left atrial appendage.

Central Message

The search for a reliable and durable surgical technique for exclusion of the left atrial appendage remains relevant in light of contemporary data.

See Editorial Commentary page 849. a variant of the internal ligation technique that aims to decrease the tension and risk of eventual dehiscence that is the mechanism of failure for internal ligations. Further, it can address appendages that have anatomies such that external clips would risk circumflex injury to achieve complete exclusion of the base. In our experience of 23 patients undergoing concomitant biatrial maze procedures for long-standing persistent atrial fibrillation, there have been no incidences of circumflex coronary injury, bleeding, or appendage tears. A case series of stapled excisions reported an appendage tear rate of $10 \% .^{3}$ In the Left Atrial Appendage Occlusion Study, the reported bleeding rate was $17.3 \%$, occurring primarily from external manipulation.

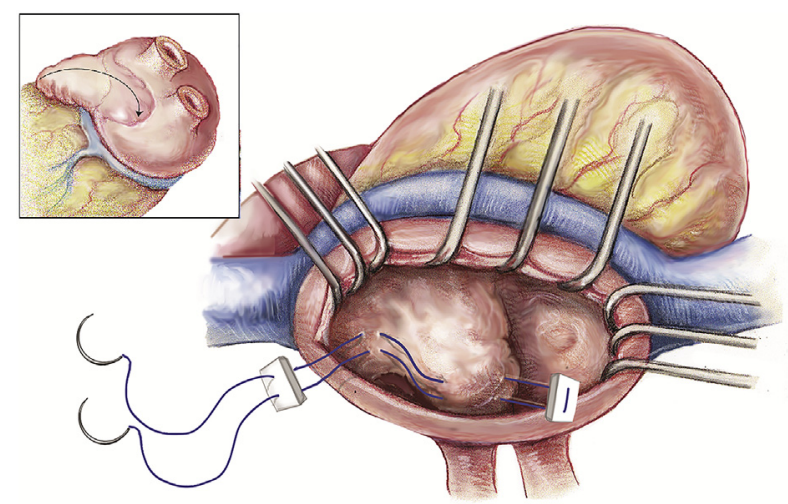

FIGURE 1. Compression suture, 4-0 polypropylene drawn through the tip and then the base of the left atrial appendage. 


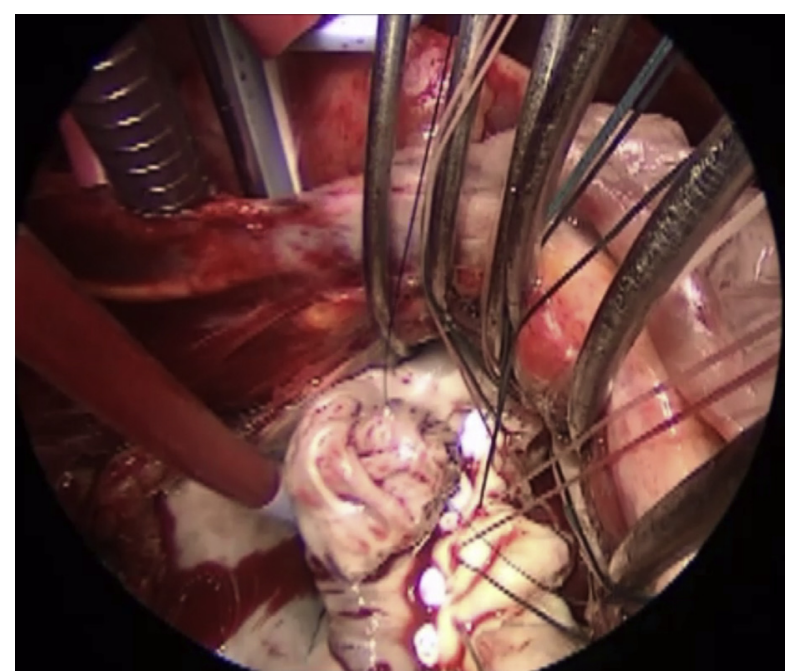

VIDEO 1. Modified internal ligation of the left atrial appendage. Video available at: http://www.jtcvsonline.org/article/S0022-5223(17)31099-1/ addons.

With regard to external clips, as we have previously reported, ${ }^{5}$ thrombus formation can still occur on a stump smaller $1 \mathrm{~cm}$, which is defined as "successful" exclusion by the criteria outlined by Kanderian and colleagues. ${ }^{6}$ The technique described here accomplishes a smoother surface and virtually no stump, which may decrease the substrate for thrombus formation. In addition, external clips add significant cost ( $\$ 1200$ at our institution, vs $\$ 15.61$ for sutures and pledgets in the technique described here). Finally, although surgical LAA excision provides the optimal management strategy for reduction of thromboembolic risk, it may not be prudent in cases in which the tissue is fragile or in reoperative cases.

As mentioned previously, the mode of failure with internal ligation may be due to tension and dehiscence. In the recent randomized study, patients undergoing internal ligation had no intraoperative bleeding complications but had a higher rate of gaps and significantly greater residual flow. ${ }^{2}$ Failures resulting from residual stumps after stapling or recanalization after internal ligation can lead to higher stroke rates at late follow-up relative to LAA excision, with a 5-fold greater risk of late neurologic events compared with nonexcisional techniques at a median occurrence time of 3.6 years $(1.13 \%$ vs $0.2 \%) .{ }^{7}$ In our experience,

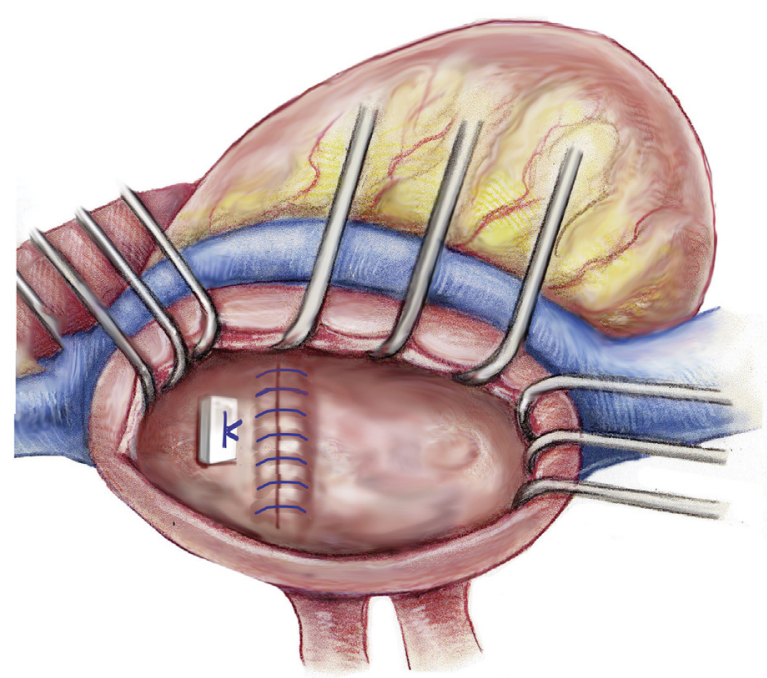

FIGURE 2. Final result after 2-layer closure of the atrial floor over left atrial appendage orifice is completed and the compression suture is tied down.

intraoperative transesophageal echocardiography has demonstrated no residual leak or stump; however, longterm follow-up is needed to determine whether this technique is equivalent or superior to excisional techniques.

The authors thank Barbara Siede for the illustrations.

\section{References}

1. Holmes DR, Kar S, Price MJ, Whisenant B, Sievert H, Doshi SK, et al. Prospective randomized evaluation of the Watchman left atrial appendage closure device in patients with atrial fibrillation versus long-term warfarin therapy: the PREVAIL trial. J Am Coll Cardiol. 2014;64:1-12. Erratum in: J Am Coll Cardiol. 2014;64:1186.

2. Lee R, Vassallo P, Kruse J, Malaisrie SC, Rigolin V, Andrei AC, et al. A randomized, prospective pilot comparison of 3 atrial appendage elimination techniques: internal ligation, stapled excision, and surgical excision. J Thorac Cardiovasc Surg. 2016;4:1075-80.

3. Gillinov AM, Pettersson G, Cosgrove DM. Stapled excision of the left atrial appendage. J Thorac Cardiovasc Surg. 2005;129:679-80.

4. Healey JS, Crystal E, Lamy A, Teoh K, Semelhago L, Hohnloser SH, et al. Left Atrial Appendage Occlusion Study (LAAOS): results of a randomized controlled pilot study of left atrial appendage occlusion during coronary bypass surgery in patients at risk for stroke. Am Heart J. 2005;150:288-93.

5. Hui DS, Alderson LJ, Lee R. Left atrial appendage thrombus after successful surgical exclusion on anticoagulation: a need for closer postintervention monitoring. Ann Thorac Surg. 2014;98:1478.

6. Kanderian AS, Gillinov AM, Pettersson GB, Blackstone E, Klein AL. Success of surgical left atrial appendage closure: Assessment by transesophageal echocardiography. J Am Coll Cardiol. 2008;52:924-9.

7. Lee R, Jivan A, Kruse J, McGee EC Jr, Malaisrie SC, Bernstein R, et al. Late neurologic events after surgery for atrial fibrillation: rare but relevant. Ann Thorac Surg. 2013;95:126-31; discussion 131-2. 